\title{
Perancangan Indikator Belok dan Perlambatan pada Helm Sepeda Berbasis Android Smartphone
}

\author{
Simon Wedhatama ${ }^{1}$, Deddy Susilo ${ }^{2}$, F. Dalu Setiaji ${ }^{3}$ \\ Program Studi Teknik Elektro, \\ Fakultas Teknik Elektronika dan Komputer, \\ Universitas Kristen Satya Wacana, Salatiga \\ ${ }^{1}$ simonwedhatama190@gmail.com, ${ }^{2}$ deddy.susilo@ymail.com, ${ }^{3} \mathrm{fdsetiaji@gmail.com}$
}

\begin{abstract}
Ringkasan
Penggunaan sepeda sebagai alat transportasi masih populer dan digemari masyarakat. Tetapi jalur khusus sepeda yang disediakan masih sangat terbatas, itu pun masih sering diserobot pengendara kendaraan bermotor sehingga dapat membahayakan pesepeda. Oleh karena itu selain pesepeda perlu menggunakan perangkat keselamaan berupa helm, diusulkan tambahan fitur pada helm tersebut untuk meningkatkan keamanan pesepeda dari kemungkinan tertabrak kendaraan lain.

Pada makalah ini helm sepeda dimodifikasi dengan menambahkan sejumlah lampu indikator (LED), yang dikendalikan oleh user interface berupa aplikasi Android smartphone yang nantinya diletakkan sepeda bagian depan sepeda yang mudah diakses pesepeda saat berkendara. Aplikasi ini dapat digunakan untuk menyalakan atau mematikan lampu sein kiri, sein kanan, lampu hazard, dan lampu depan, serta terdapat tampilan speedometer untuk mengetahui kecepatan sepeda dalam satuan $\mathrm{km} / \mathrm{jam}$ atau $\mathrm{m} / \mathrm{s}$. Lampu indikator perlambatan juga akan menyala bila sepeda mengalami perlambatan sekitar $-1 \mathrm{~m} / \mathrm{s}^{2}$.
\end{abstract}

Kata Kunci : Bluetooth; lampu indikator; Android smartphone; helm pesepeda.

\section{Pendahuluan}

Pada masa sekarang, sepeda masih banyak dipergunakan di jalan raya sebagai alat transportasi yang murah, sehat, hemat energi serta ramah lingkungan karena tidak menimbulkan polusi udara. Tetapi saat ini jalur khusus sepeda yang disediakan belum memadai[1]. Jalur khusus sepeda yang telah ada juga banyak beralih fungsi sebagai sarana parkir kendaraan bermotor. Mobil dan motor pun sering menyerobot jalur khusus sepeda sehingga pesepeda menjadi terpinggirkan [2]. Akibatnya pesepeda terpaksa berkendara di jalur utama jalan raya bersama pengendara bermotor lainnya. Selain berbahaya bagi pesepeda, pengendara bermotor juga akan sulit memprediksi kemana pesepeda akan berbelok arah terlebih pada malam hari karena tidak adanya lampu sein.

Oleh karena itu selain pesepeda harus menggunakan perangkat keselamatan yang telah ada, dibutuhkan fitur tambahan untuk menunjang keselamatan dalam bersepeda. Maka pada makalah ini dirancang sebuah alat pengaman tambahan pada helm yang dapat berfungsi seperti lampu sein agar arah pesepeda mudah dilihat pengendara motor atau mobil. Alat yang dibuat dapat dikendalikan dengan mudah melalui Android smartphone yang terkoneksi secara nirkabel. 
Alat serupa yang diusulkan juga telah dibuat misalnya [3], namun alat tersebut lebih sederhana, yaitu hanya terdapat dua lampu sein pada helm yang dapat diaktifkan secara nirkabel (tidak dijelaskan jenis transmisi nirkabelnya) melalui saklar yang terkadang tidak merespons saat ditekan. Ada juga perangkat komersial yang disebut Lumos Helmet, yang menjadi salah satu dari The Best Cycling Innovations 2015 [4]. Lumos Helmet dibuat agar para pesepeda tetap aman di jalan. Helm tersebut dilengkapi dengan indikator peringatan saat pesepeda memperlambat kecepatan dan saat berbelok. Perbandingan antara alat yang dibuat dengan Lumos Helmet ditunjukkan oleh Tabel 1.

Tabel 1. Perbandingan alat yang dibuat dengan Lumos Helmet.

\begin{tabular}{|l|c|c|}
\hline & Alat yang dibuat & LUMOS HELMET \\
\hline Indikator perlambatan & Ada & Ada \\
\hline Indikator belok kiri & Ada & Ada \\
\hline Indikator belok ke & Ada & Ada \\
\hline Lampu depan & $\begin{array}{c}\text { Ada (sebagai indikator } \\
\text { dan penerangan) }\end{array}$ & Ada (sebagai indikator) \\
\hline Lampu hazard & Ada & Ada \\
\hline User interface & Android smartphone & Tombol tekan \\
\hline Tombol sein kiri & Ada & Ada \\
\hline Tombol sein kanan & Ada & Tidak ada \\
\hline Tombol hazard & Ada & Tidak ada \\
\hline Tombol lampu depan & Ada & Tidak ada \\
\hline Speedometer & Ada & \\
\hline
\end{tabular}

Terlihat dari Tabel 1 terdapat sejumlah perbedaan terutama pada user interface yang dipakai. Alat yang dibuat menggunakan Android smartphone sebagai user interface nya yang tidak hanya dipakai sebagai alat untuk memberikan intruksi, tetapi juga sebagai tampilan untuk menginformasikan laju sepeda yang dikendarai pada pengguna.

\section{Perancangan}

Alat yang dirancang adalah berupa sebuah helm sepeda yang dimodifikasi yaitu dilengkapi dengan sejumlah LED yang berfungsi sebagai lampu sein kiri, lampu sein kanan, lampu hazard, lampu depan dan LED indikator perlambatan. Alat memiliki user interface berupa aplikasi Android yang layarnya dapat menampilkan laju sepeda (speedometer) sekaligus digunakan sebagai papan tombol untuk mengendalikan LED pada helm.

Pengendalian dilakukan menggunakan modul Bluetooth dipasang pada helm agar dapat berkomunikasi dengan aplikasi Android smartphone. Terdapat pula sensor percepatan untuk mengukur percepatan sepeda yang nantinya digunakan untuk menyalakan LED indikator perlambatan.

Bagian-bagian penyusun alat yang dibuat ditunjukkan Gambar 1. Secara garis besar, data yang diperoleh dari sensor akselerometer ADXL 345 akan diolah oleh mikrokontroler menjadi data percepatan yang akan menyalakan LED indikator saat sepeda mengalami perlambatan. Android smartphone digunakan pengguna untuk memberikan instruksi pada mikrokontroler Arduino Nano secara nirkabel melalui modul Bluetooth HC-05 untuk menyalakan atau mematikan lampu sein kiri, lampu sein kanan, lampu hazard, dan lampu depan. 


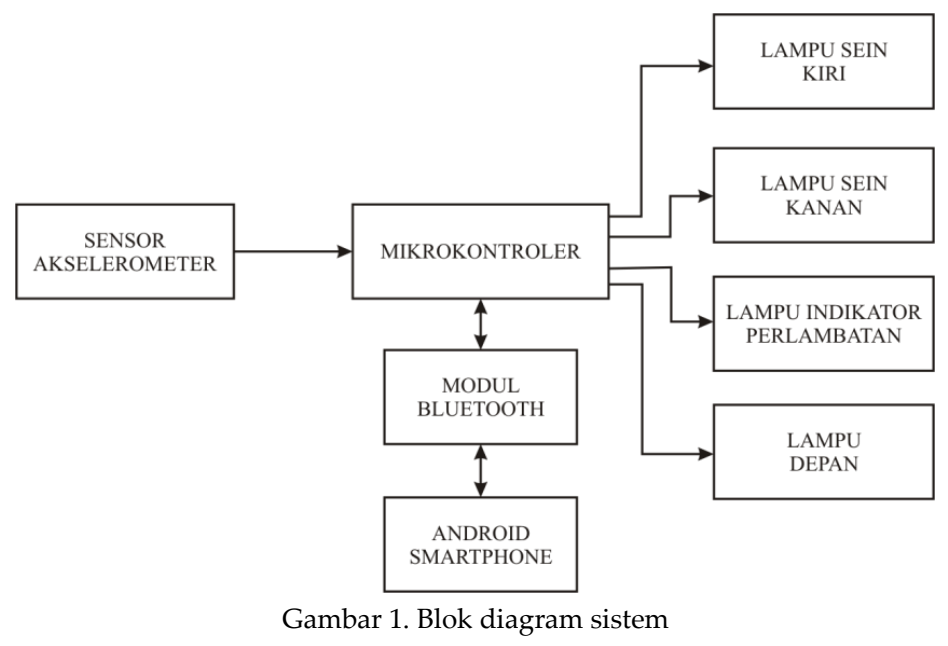

\subsection{Perancangan Perangkat Keras}

Gambar 2 dan 3 adalah sketsa helm sepeda yang sudah dimodifikasi.

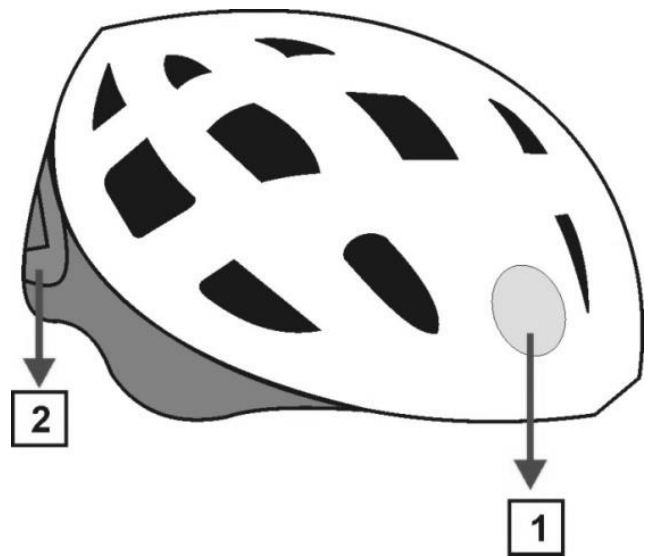

Gambar 2. Gambar sketsa helm tampak depan.

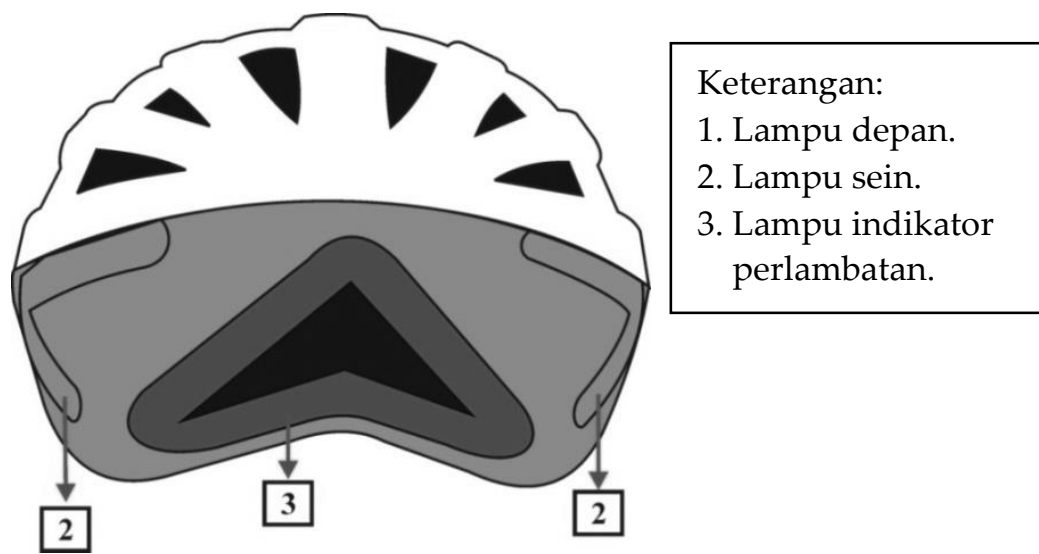

Gambar 3. Gambar sketsa helm tampak belakang. 
Foto jadi helm sepeda yang sudah dimodifikasi ditunjukkan Gambar 4.

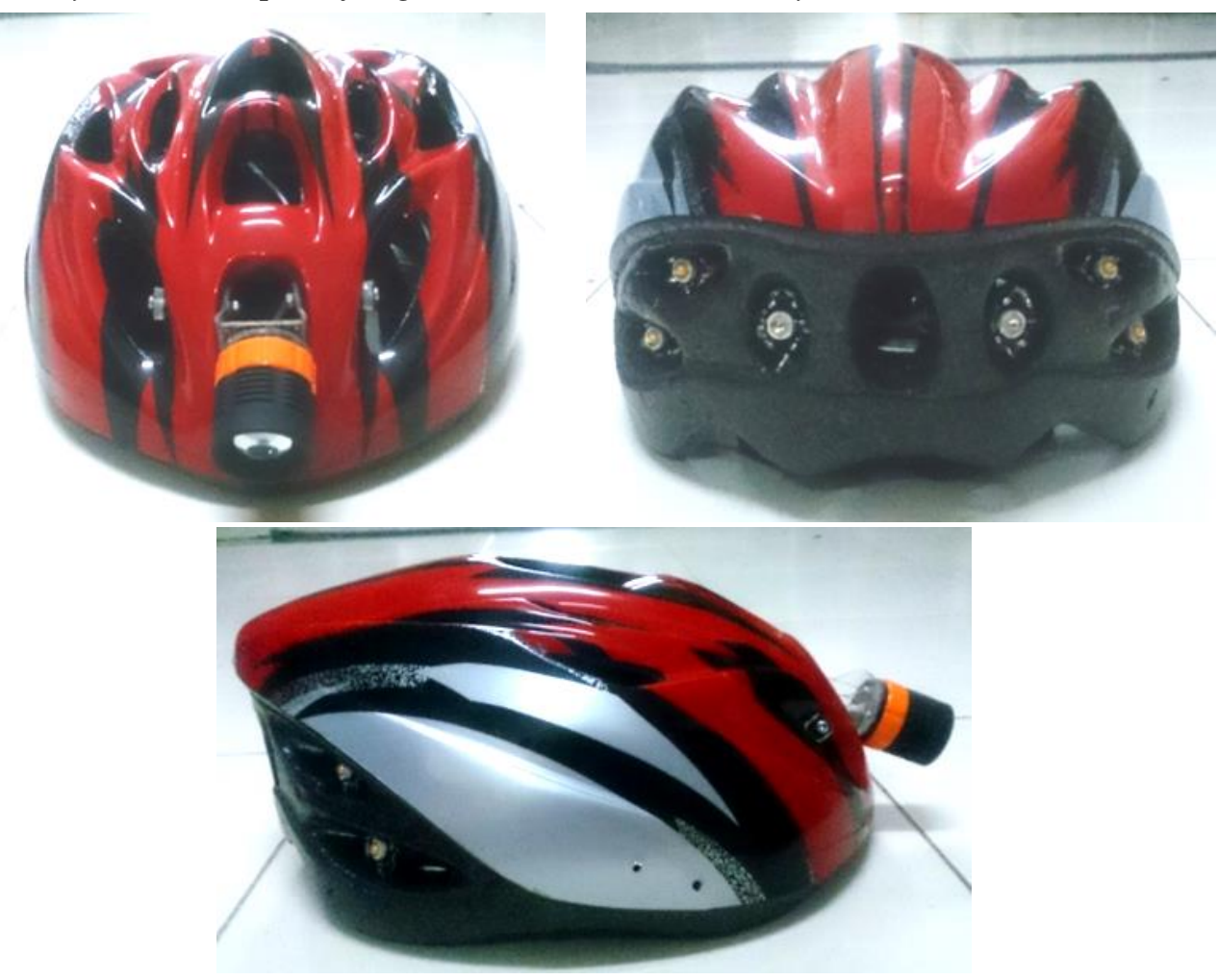

Gambar 4. Foto helm yang sudah dimodifikasi

\subsubsection{Pengendali Utama}

Pengendali utama menggunakan board Arduino Nano dengan IC mikrokontroler ATmega 328, yang bertugas antara lain: mengambil dan mengolah data sensor akselerometer, melakukan komunikasi dengan android smartphone melalui media Bluetooth untuk menyalakan atau mematikan LED-LED helm.

\subsubsection{Akselerometer Digital ADXL 345 [5]}

Sensor akselerometer digunakan untuk mengukur percepatan translasi yang dialami oleh pesepeda. Saat sepeda mengalami perlambatan maka sensor akan memberikan informasi pada mikrokontroler untuk menyalakan LED indikator perlambatan.

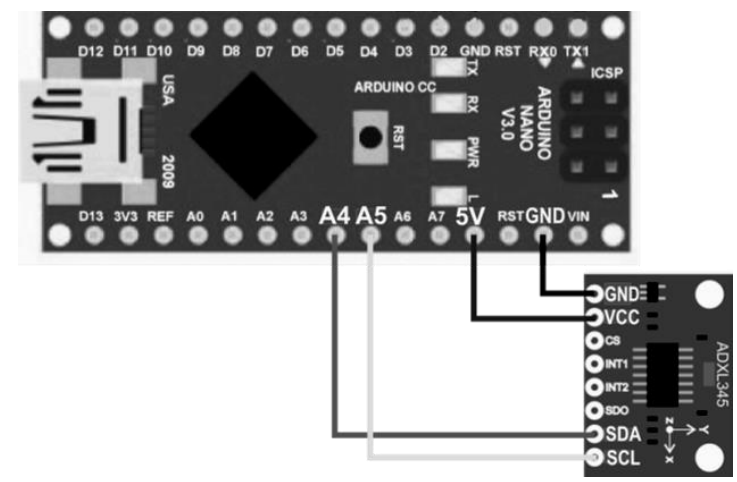

Gambar 5. Skema konfigurasi pin ADXL 345 dengan Arduino Nano 


\subsubsection{Bluetooth HC-05 [6]}

Komunikasi antara Android smartphone dengan mikrokontroler yang terdapat pada helm dilakukan secara nirkabel, menggunakan Bluetooth HC-05 sebagai sarana pengiriman data.

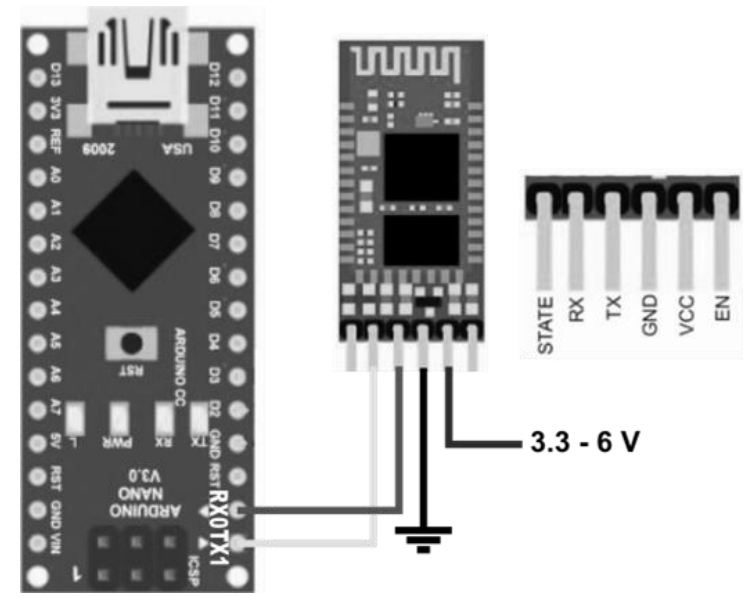

Gambar 6. Skema konfigurasi pin Bluetooth HC-05 dengan Arduino Nano

\subsection{Perancangan Perangkat Lunak}

Pada bagian ini akan dijelaskan mengenai perangkat lunak yang digunakan yaitu perancangan program mikrokontroler sebagai pengendali utama dan aplikasi user interface Android smartphone.

\subsubsection{Program Mikrokontroler}

Program diawali dengan pengambilan data dari sensor akselerometer dan mengolahnya, jika pesepeda mengalami perlambatan LED indikator perlambatan akan dinyalakan. Kemudian program akan membaca intruksi dari Andoid smarphone, yaitu instruksi untuk memilih LED indikator mana yang akan dinyalakan. Setelah program menyalakan indikator sesuai yang diperintahkan ataupun program tidak mendapatkan intruksi dari android smartphone, maka program akan kembali melakukan pengambilan data sensor akselerometer.

\subsubsection{Aplikasi User Interface Android Smartphone}

Aplikasi user interface ini (Gambar 8) merupakan aplikasi Android untuk mengendalikan LED-LED pada helm serta untuk menampilkan kecepatan pesepeda.

Penjelasan tiap bagian dari aplikasi user interface adalah sebagai berikut:

A: Tombol untuk menyalakan dan mematikan lampu depan.

B: Tampilan nomor "1" adalah untuk menunjukkan kecepatan yang dialami pesepeda. Dan nomor "2" adalah tampilan check box untuk memilih satuan kecepatan yang digunakan yaitu dalam $\mathrm{km} / \mathrm{h}$ atau $\mathrm{m} / \mathrm{s}$.

C: Untuk menyalakan sein kiri, sein kanan, dan lampu hazard pengguna memberikan perintah dengan cara menggeser (slide) pada layar android.

D: Tombol untuk mematikan lampu sein kiri, sein kanan, dan lampu hazard.

Gambar 9 menunjukkan diagram alir program aplikasi user interface. 


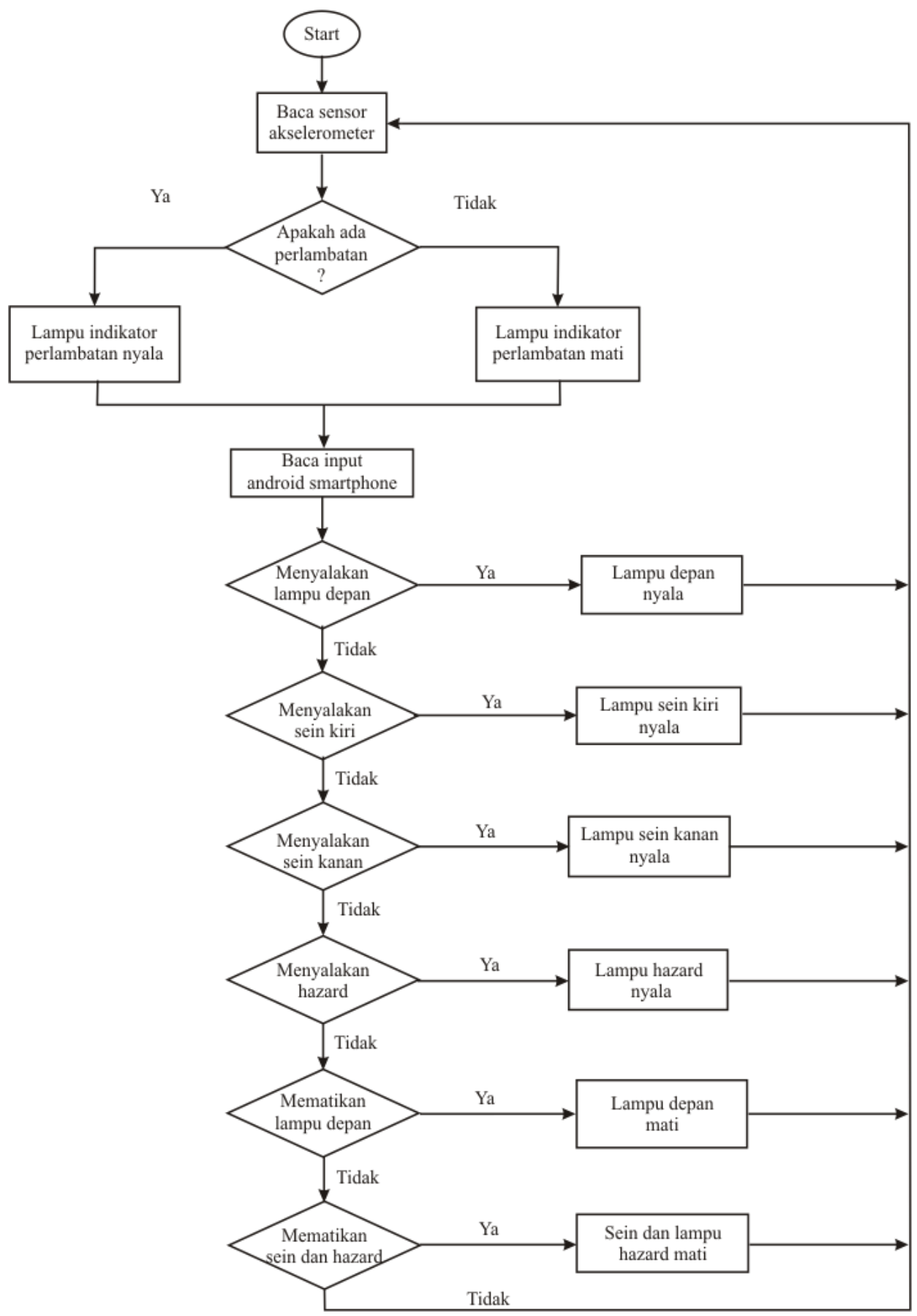

Gambar 7. Diagram alir program mikrokontroler 


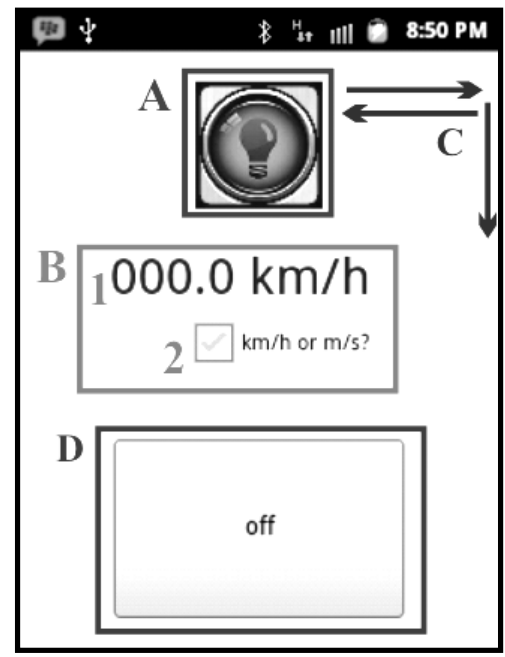

Gambar 8. Tampilan aplikasi user interface Android.

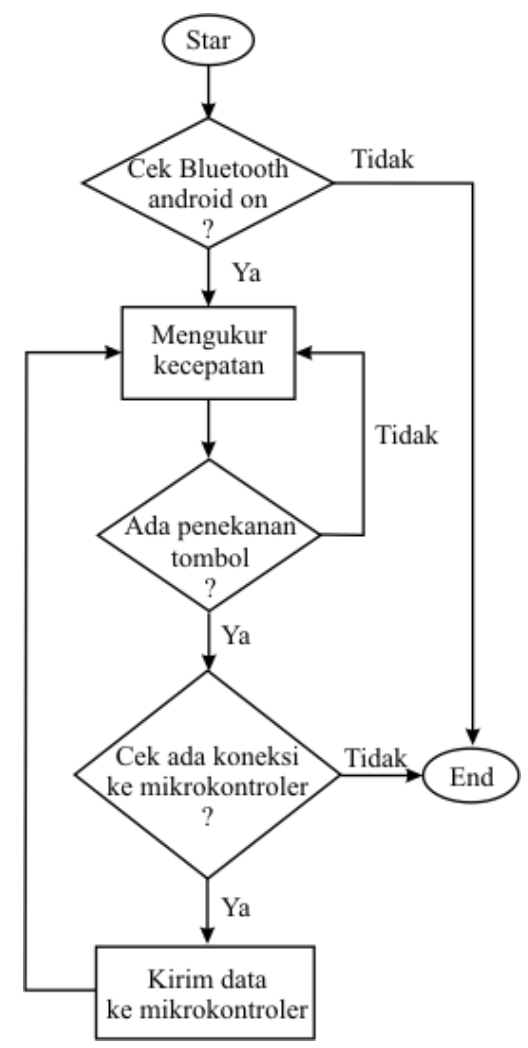

Gambar 9. Diagram alir user interface.

\section{Pengujian}

Pada bagian ini akan dibahas mengenai pengujian alat beserta analisisnya.

\subsection{Pengujian Sinkronisasi}

Pengujian sinkronisasi dilakukan dengan melakukan pairing antara Android smartphone dengan modul Bluetooth HC-05 yang tersambung pada mikrokontroler. Proses ini dilakukan menggunakan aplikasi "Bluetooth Setting" yang terdapat pada Android 
smartphone. Aplikasi akan mendeteksi Id Bluetooth pada modul HC-05, setelah terdeteksi dan melakukan sinkronisasi, Android smartphone siap berkomunikasi dengan mikrokontroler. Pengujian ini berhasil dengan baik setiap kali sinkronisasi dilakukan.

\subsection{Pengujian Aplikasi User Interface}

Pada bagian ini dilakukan pengujian terhadap aplikasi user interface yang telah dibuat.

\subsubsection{Pengujian Lampu Sein dan Lampu Hazard}

Pengujian pengendalian lampu sein kiri dilakukan dengan cara menggeser (slide) layar smartphone (Gambar 8) ke kiri. Lampu LED sein kiri akan menyala. Kemudian untuk mematikannya dengan cara menekan tombol "OFF". Pengujian pengendalian lampu sein kanan dilakukan dengan cara serupa namun dilakukan dengan menggeser layar ke kanan. Untuk lampu hazard pengendaliannya dilakukan dengan menggeser ke bawah. Hasil pengujian menunjukkan bahwa semua lampu bisa dihidupmatikan melalui layar smartphone dengan baik.

\subsubsection{Pengujian Tombol Lampu Depan}

Pengujian dilakukan pada kondisi awal lampu depan pada keadaan mati. Setelah dilakukan penekanan pada tombol lampu depan (tombol $A$ pada Gambar 8), lampu depan akan menyala dan tombol $A$ berubah warna menjadi hijau (Gambar 10). Kemudian untuk mematikannya dengan cara menekan kembali tombol lampu depan, dan warna tombol $A$ menjadi abu-abu. Hasil pengujian menunjukkan bahwa lampu depan bisa dihidupmatikan melalui layar smartphone dengan baik.
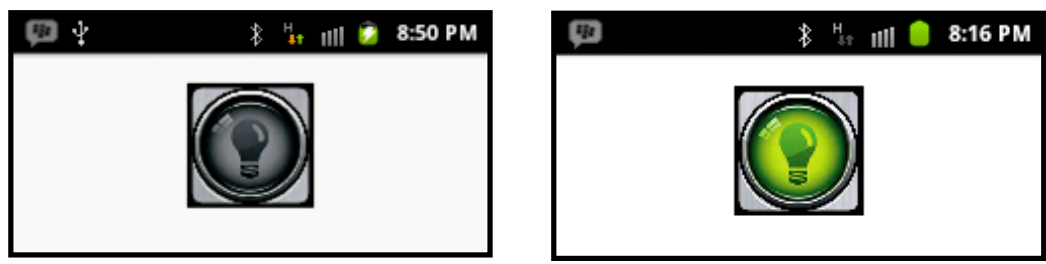

Gambar 10. Gambar tombol lampu depan saat mati (kiri) dan saat hidup (kanan)

\subsubsection{Pengujian Speedometer}

Pengujian terdiri dari dua bagian yaitu pengujian pemilihan satuan kecepatan yang dipakai dan pengujian speedometer. Pengujian pemilihan satuan kecepatan dilakukan dengan cara menekan pada menu checkbox. Bila checkbox tercentang menggunakan satuan $\mathrm{m} / \mathrm{s}$ dan bila checkbox tidak tercentang menggunakan satuan $\mathrm{km} / \mathrm{h}$, seperti ditunjukkan Gambar 11.
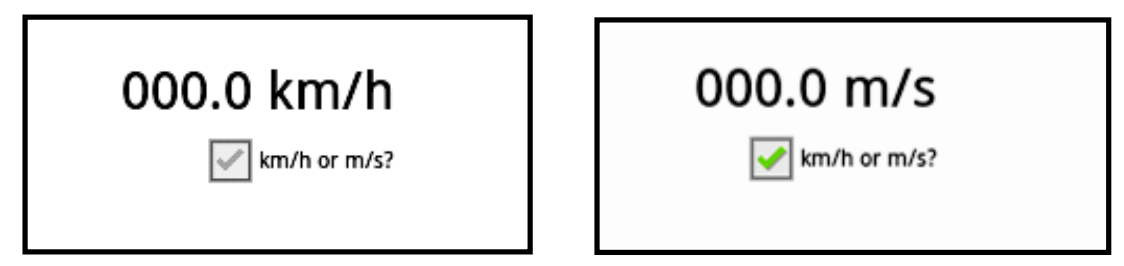

Gambar 11. Speedometer bisa menggunakan satuan km/h (kiri) dan m/s (kanan)

Kemudian pengujian speedometer dilakukan dengan cara menggunakan helm yang telah dimodifikasi lalu menjalankan sepeda. Laju sepeda yang terukur akan 
dibandingkan dengan aplikasi speedometer yang telah tersedia di Play Store yaitu DigiHUD Speedometer, yang ditunjukkan Gambar 12.

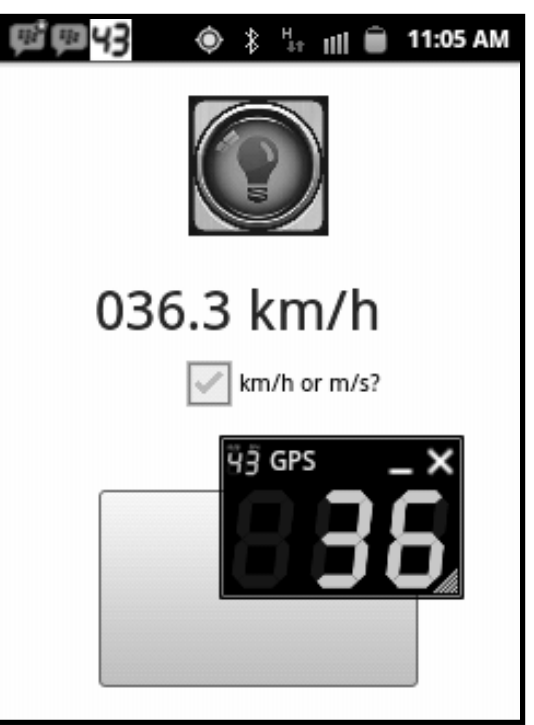

Gambar 12. Pengujian fitur Speedometer dibandingkan dengan DigiHUD Speedometer

Hasilnya, pengukuran menggunakan speedometer yang dibuat cukup akurat dengan perbedaan maksimal 3\% seperti ditunjukkan Tabel 2.

Tabel 2. Perbandingan laju sepeda.

\begin{tabular}{|c|c|c|}
\hline $\begin{array}{l}\text { DidiHUD Speedometer } \\
(\mathbf{k m} / \mathbf{h})\end{array}$ & $\begin{array}{l}\text { Speedometer yang dibuat } \\
(\mathrm{km} / \mathrm{h})\end{array}$ & Perbedaan $(\%)$ \\
\hline 0 & 0 & 0 \\
\hline 5 & 4,9 & 2 \\
\hline 10 & 10,2 & 2 \\
\hline 15 & 15,1 & 0,7 \\
\hline 20 & 20,0 & 0 \\
\hline 25 & 25,2 & 0,8 \\
\hline 30 & 29,9 & 3 \\
\hline 35 & 35,2 & 0,6 \\
\hline 40 & 40,3 & 0,8 \\
\hline
\end{tabular}

\subsubsection{Pengujian Sensor Akselerometer}

Pengujian sensor akselerometer dilakukan untuk menguji apakah lampu indikator perlambatan dapat menyala ketika sepeda mengalami perlambatan.

Hasil pengujian Tabel 3 menunjukkan bahwa lampu indikator perlambatan menyala ketika sepeda mengalami perlambatan (percepatannya negatif) sekitar $-1 \mathrm{~m} / \mathrm{s}^{2}$ sesuai yang diinginkan.

\subsection{Pengujian Baterai}

Pengujan baterai dilakukan untuk mengetahui berapa lama baterai dapat bertahan mengaktifkan alat yang dibuat. Setelah dilakukan pengujian dengan baterai merk Asus kapasitas $9800 \mathrm{mAh}$, tegangan keluaran 5 volt, diketahui baterai dapat mencatu alat selama 16 jam, atau daya alat sekitar 3,1W. 
Tabel pengujian lampu indikator perlambatan

\begin{tabular}{|c|c|c|c|}
\hline $\begin{array}{c}\text { Pengereman } \\
\text { Ke- }\end{array}$ & $\begin{array}{c}\text { Percepatan Sebelum } \\
\text { sepeda direm }(\mathrm{m} / \mathrm{s} 2)\end{array}$ & $\begin{array}{c}\text { Percepatan Setelah } \\
\text { sepeda direm }(\mathrm{m} / \mathrm{s} 2)\end{array}$ & $\begin{array}{c}\text { Kondisi Lampu } \\
\text { Indikator Perlambatan }\end{array}$ \\
\hline 1 & 0,23 & $-1,15$ & nyala \\
\hline 2 & 0,08 & $-1,87$ & nyala \\
\hline 3 & 0,61 & $-2,02$ & nyala \\
\hline 4 & 0,11 & $-1,10$ & nyala \\
\hline 5 & 0,04 & $-1,36$ & nyala \\
\hline 6 & 1,22 & $-1,38$ & nyala \\
\hline 7 & 0,97 & $-1,98$ & nyala \\
\hline 8 & 1,18 & $-1,30$ & nyala \\
\hline 9 & 1,30 & $-2,06$ & nyala \\
\hline 10 & 0,87 & $-1,03$ & \\
\hline
\end{tabular}

\section{Kesimpulan}

Berdasarkan perancangan, perealisasian serta pengujian yang telah dilakukan dapat ditarik beberapa kesimpulan sebagai berikut ini.

1. Helm sepeda yang telah dimodifikasi tetap dapat digunakan sebagai pelindung kepala pesepeda sekaligus dapat berfungsi sebagai lampu penerangan depan sepeda, lampu sein, dan indikator perlambatan, yang membantu pengendara lain memprediksi arah dan laju pesepeda.

2. Aplikasi yang dibuat di Android smartphone dapat menampilkan laju sepeda dalam satuan $\mathrm{km} / \mathrm{h}$ atau $\mathrm{m} / \mathrm{s}$, telah diuji sampai $40 \mathrm{~km} / \mathrm{h}$ atau $11 \mathrm{~m} / \mathrm{s}$ dengan ralat maksimal sekitar $3 \%$.

3. Konsumsi daya alat yang dibuat adalah sekitar 3,1 watt.

\section{Daftar Pustaka}

[1] Dwi Sulistyo, dkk, Upaya Penggunaan Sepeda Sebagai Moda Transportasi di Kota Surabaya, Proceeding PESAT, Univ. Guna Darma, Depok, 18-19 Oktober 2011.

[2] Rahmah Hayati, Jalur Khusus Pesepeda di Yogyakarta Tidak Efektif Tuh! [Online] http://www.kompasiana.com/rahmah_hayati/jalur-khusus-pesepedadi-yogyakarta-tidak-efektif-tuh_54f8e35ea333112d3c8b477d

(diakses 17 September 2017)

[3] Naufal RAR, Nadia S, Portable Wireless Sign Lamp For Bicycle Helmet, Seminar Nasional Teknologi Informasi dan Multimedia 2016, STMIK AMIKOM, Yogyakarta, 6-7 Februari 2016.

[4] Anonim,"Lumos Helmet - A Next Generation Bicycle Helmet", [Online] https://www. lumoshelmet.co/ (diakses 17 September 2017)

[5] Anonim, 3-Axis, $\pm 2 \mathrm{~g} / \pm 4 \mathrm{~g} / \pm 8 \mathrm{~g} / \pm 16 \mathrm{~g}$ Digital Accelerometer ADXL345 [Data Sheet Rev.D], Analog Devices, 2013.

[6] Anonim, "HC Serial Bluetooth Products User Instructional Manual," http://www.tec.reutlingen-university.de/uploads/media/ DatenblattHC-05 BT-Modul.pdf (diakses 17 September 2017) 